\title{
Effect of Different Loading Conditions on the Service Life of Mine Steel Wire in Corrosive Medium
}

\author{
Songquan Wang ${ }^{1, *}$, Dekun Zhang $^{2}$, Ningning $\mathrm{Hu}^{1}$, Jialu Zhang ${ }^{1}$ \\ ${ }^{1}$ School of Mechatronic Engineering, JiangSu Normal University, Xuzhou 221116 \\ ${ }^{2}$ School of Materials Science and Engineering, China University of Mining and Technology, Xuzhou \\ 221116 \\ *E-mail: wbplsz@163.com
}

doi: $10.20964 / 2016.06 .15$

Received: 12 January 2016 / Accepted: 23 March 2016 / Published: 4 May 2016

\begin{abstract}
Long-term corrosion test, constant tensile test and corrosion fatigue test of steel wire were carried out in this paper. According to the results of parameters of electrochemical corrosion, equivalent stress distribution of pit bottom, and morphology of steel wire surface and fracture, the coupled action of stress and corrosion on the failure of mine steel wire was discussed. It was found that the corrosion current density of steel wire in the initial phase of corrosion fatigue test was about 20 times higher than that in long-term corrosion test, and the radio increased for the effect of the cyclic load during the test, which also showed that the corrosion rate of steel wire would be greatly increased by the load. In addition, the equivalent stress distribution of pit bottom was related to the load and corrosion degree, and equivalent stress value appears to be associated with this effect which marginally increases with increasing corrosion degree of steel wire under the same load. The corrosion of surface was strengthened with the increase of load, and cyclic stress may result in crack formation. Meanwhile, the brittleness of steel wire increased under the interaction of load and corrosion. Obvious plastic deformation was not observed in corrosion fatigue test, but brittle completely.
\end{abstract}

Keywords: Steel wire; corrosion rate; stress corrosion cracking; corrosion fatigue; finite element model

\section{$\underline{\text { FULL TEXT }}$}

(C) 2016 The Authors. Published by ESG (www.electrochemsci.org). This article is an open access article distributed under the terms and conditions of the Creative Commons Attribution license (http://creativecommons.org/licenses/by/4.0/). 